\title{
TRANEXAMIC ACID IN PATIENTS WITH GREEN SNAKE BITE IN WESTERN REGION OF NEPAL
}

\author{
Sapkota $S^{1^{*}}$, Acharya $R R^{1}$, Paudel $N^{1}$
}

\section{Affiliation}

1. Lecturer, Department of Internal Medicine, Manipal College of Medical Sciences, Pokhara, Nepal

\section{ARTICLE INFO \\ Article History \\ Received : 28 January, 2018 \\ Accepted : 10 March, 2018 \\ Published : 30 April, 2018}

(c) Authors retain copyright and grant the journal right of first publication with the work simultaneously licensed under Creative Commons Attribution License CC - BY 4.0 that allows others to share the work with an acknowledgment of the work's authorship and initial publication in this journal.

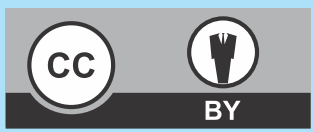

ORA 53

DOI: http://dx.doi.org/10.3126/bjhs.v3i1.19739

\author{
* Corresponding Author \\ Dr. Subash Sapkota \\ Lecturer \\ Department of Internal Medicine \\ Manipal College of Medical sciences, Pokhara, Nepal \\ Email:subash76@gmail.com \\ https://orcid.org/0000-0001-8588-5626
}

\section{Citation}

Sapkota S, Acharya RR, Paudel N. Tranexamic Acid in Patients with Green Snake Bite in Western Region of Nepal. BJHS 2018;3(1)5 : 346 - 349.

\section{ABSTRACT}

\section{Introduction}

Green snakes found in hilly areas of Nepal cause significant morbidity in form of local swelling and bleeding manifestations. Polyvalent antivenoms are not indicated for the treatment. Specific management protocols are not endorsed for its bite. Conventionally, vitamin $\mathrm{K}$ and fresh frozen plasma are used to correct deranged coagulation in green snake bite.

\section{Objectives}

The objective of this study was to evaluate the effectiveness of addition of tranexamic acid to the conventional method in green snake bite in western region of Nepal.

\section{Methodology}

A hospital based, prospective comparative cross-sectional study was conducted at Department Medicine Manipal Teaching Hospital, Pokhara, Nepal from April 2014 to October 2017. It included 110 patients aged 15 to 76 years of both genders with confirmed history of green snake bite. Participants were alternately randomized into two groups; conventional group, tranexamic acid group. Duration of hospital stay was considered the primary outcome measure for this study while INR levels were considered the secondary outcome measure. Data were collected in a preformed pro forma and analyzed using SPSS version 16.0. Differences were considered significant if $p$-value is $<0.05$.

\section{Results}

The age (mean: $35.41 ; S D=17.23$ ) of the study population ranged from $15-76$ years. The median duration of hospital stay in conventional group was 8 days (Inter Quartile Range = 7 to 8 ) and in tranexamic acid group was 6 days (Inter Quartile Range: 5 to 6). Mean INR was statistically significantly different at day 5 and day 6 in favor of tranexamic acid group $(p<0.001)$

\section{Conclusion}

Treatment with tranexamic acid reduced the median duration of hospital stay by two days. Statistically significant differences in mean International Normalized Ratio levels were seen at day 5 and 6 of hospitalization $(p<0.001)$.

\section{KEYWORDS}

Hospital stay, international normalized ratio, snake bite, tranexamic acid 


\section{INTRODUCTION}

Snakebite is a medical emergency and a preventable public health hazard in most part of Nepal. ${ }^{1,2}$ Green snakes (Ahaetulla nasuta) commonly found in hilly areas are mildly venomous and can cause swelling, pain, bruising, numbness, bleeding and destruction of local tissue by not letting blood clot leading to significant morbidity. The ingredients of the venom are unknown; hence it may be an avenue for further research. ${ }^{3,4}$ There is no evidence that the polyvalent snake antivenoms have any effect on green snakes of Nepal..$^{5}$

Specific guidelines are not available for the management of green snakes bite. It may be rational to use fresh frozen plasma, vitamin-K for hematological disturbances manifested as elevated International Normalized Ratio (INR) level and antibiotics for cellulitis. Corticosteroids, heparin, aprotinin, antihistamine, trypsin and a variety of traditional herbal remedies have been used and advocated by different people. However, many of them are potentially harmful and none have been proved to be effective. ${ }^{6}$

To promote coagulation by inducing the coagulation cascade, antifibrinolytics like tranexamic acid or aminocaproic acid work together with clotting factors and Vitamin-K. Tranexamic acid is a synthetic antifibrinolytic, which acts by reversibly binding lysine receptor sites on plasminogen or plasmin and preserves the framework of fibrin's matrix structure. It has roughly eight times the antifibrinolytic activity of an older analogue aminocaproic acid. ${ }^{7}$

The objective of this study is to find out whether adding tranexamic acid to the conventional management in green snake bite confers additional benefit.

\section{METHODOLOGY}

This is a hospital based, prospective comparative cross sectional study conducted at Department of Medicine, Manipal Teaching Hospital, Pokhara, Nepal from April 2014 to October 2017. Study was carried out after obtaining approval from Institutional Review Committee (IRC) of the institute. Patients admitted to the medicine department of hospital with the confirmed history of green snake bite and those who gave consent for the study were included. Those cases where type of snake was not clear, patients with bleeding disorders, under anticoagulants and those who didn't give consent were excluded. Patients included in the study were alternately assigned into two groups. One group was given the conventional treatment (Fresh frozen plasma + Vitamin-K) whereas the other group received injection tranexamic acid 500mg intravenous 8 hourly as add on treatment. Daily International normalized ratio (INR) levels were monitored. Participants were considered eligible for discharge on the same day only after their INR level had normalised. The INR of less than or equal to 1.5 was considered normal.Duration of hospital stay was considered the primary outcome measure for this study while INR levels were considered the secondary outcome measure. Sociodemographic profile, clinical features and other relevant data were collected in a preformed pro forma and analyzed using SPSS version 16.0. All differences were considered significant if $p$-value is $<0.05$.

\section{RESULTS}

A total of 110 participants (55 in each group) were included in the study. The age of the study population ranged from $15-76$ years ( $m e a n=35.41 ; S D=17.23$ ). The mean age of the participants in the conventional group was 33.41 $(S D=16.41)$ years and $36.71(S D=18.29)$ years in the tranexamic acid group. There was no statistically significant difference between the age in these two groups $(p=0.323)$. Out of 110 participants $56.4 \%(n=62)$ were females and $43.6 \%(n=48)$ were males. Clinical features of patients included in the study have been presented below in table 1.

\begin{tabular}{|c|c|}
\hline Symptoms & Number of patients (\%)* \\
\hline Pain and swelling & $98(89.1 \%)$ \\
\hline Bleeding & $50(45.5 \%)$ \\
\hline Palpitation & $22(20 \%)$ \\
\hline Dizziness & $16(14.5 \%)$ \\
\hline
\end{tabular}

* the total percentage exceeds 100 because multiple symptoms were present in the same patient.

The median duration of hospital stay in conventional group was 8 days (IQR=7 to 8 ) and in tranexamic acid group was 6 days (IQR=5 to 6$)$. There was statistically significant difference in median duration of hospital stay as shown in table 2 .

\begin{tabular}{|c|c|c|c|c|}
\hline & Conventional & $\begin{array}{l}\text { Tranexamic } \\
\text { acid }\end{array}$ & $\begin{array}{c}\text { Test } \\
\text { statistics* }\end{array}$ & $p$-value \\
\hline Median(IQR) & $8(7-8)$ & $6(5-6)$ & $U=545.5$ & $<0.001$ \\
\hline
\end{tabular}

*test statistics (U) obtained using Independent sample T test and Mann-Whitney $U$ test.

The details of patients discharged on different days are presented in table 3. As shown in table higher number of patients from tranexamic acid group were discharged on day 5 and day 6 . 


\begin{tabular}{|}
$\begin{array}{r}\text { Table 3: Frequency of patients discharged on different } \\
\text { days }(n=110)\end{array}$ \\
\hline $\begin{array}{c}\text { Day of hospital } \\
\text { stay }\end{array}$ & $\begin{array}{c}\text { Conventional group } \\
(n=55)\end{array}$ & $\begin{array}{c}\text { Tranexamic } \\
\text { acid group }(n=55)\end{array}$ \\
\hline 5 & $5(9 \%)$ & $15(27 \%)$ \\
\hline 6 & $4(7 \%)$ & $28(51 \%)$ \\
\hline 7 & $11(20 \%)$ & $6(11 \%)$ \\
\hline 8 & $35(64 \%)$ & $6(11 \%)$ \\
\hline
\end{tabular}

Our secondary outcome measure was international normalized ratio. Mean INR was significantly different at day 5 and day 6 in favor of tranexamic acid group $(p<0.001)$. However, at other time points there was no statistically significant difference in mean INR in these groups. From day 1 to day 4 the INR values which were reported as "did not clot" have been excluded from the analysis. Similarly some proportions of patients were discharged from $5^{\text {th }}$ day onwards hence the number of patients in each groups are different for different days except for day 5. At day 5 none of the reports in both groups were reported as "did not clot" and patients were discharged on $5^{\text {th }}$ day only after obtaining INR reports. Hence, we were able to include data of all 110 patients for day 5. At day 5, the INR of all patients in both the groups were within the reporting range. From day 6 onwards, INR was not done for those patients whose INR had normalized. The means of INR in both groups at different time points are shown in figure 1.

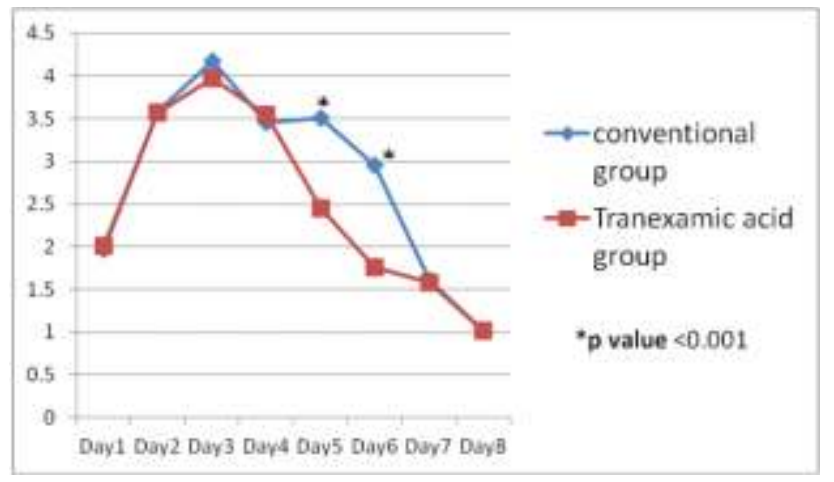

Figure 1: Comparison of means of daily INR in both the groups.

\section{DISCUSSION}

A prospective comparative cross sectional study was done in a tertiary hospital of western region of Nepal. Total of 110 participants with history of green snake bite were included in the study. Half of these patients were randomized to get the conventional management and the other half received injection tranexamic acid as add on treatment. The age was ranged 15-76 years because the study was carried out under medicine department only. Females slightly out number males in the current study group. Pain and swelling remain the main symptoms of these patients followed by bleeding as shown in table 1.

In this study, tranexamic acid group showed significantly lower median duration of hospital stay compared to the conventional group $(p<0.001)$ as shown in table 2 . Majority of patients $43 / 55$ (78\%) who received tranexamic acid were discharged on $5^{\text {th }}$ and $6^{\text {th }}$ day compared to only $9 / 55(16 \%)$ in conventional group which was shown in table 3 . When we compared mean INR level in these two groups there was no statistical difference in initial days from day 1 to 4 . However, tranexamic acid lowered INR significantly from $5^{\text {th }}$ day onward. On $5^{\text {th }}$ and $6^{\text {th }}$ day the reduction of INR was significantly different than the conventional group $(p<0.001)$. This difference was however not seen on $7^{\text {th }}$ and $8^{\text {th }}$ day. This finding indicates that tranexamic acid helps to normalize the INR level earlier than in the conventional group which is the secondary outcome measure of this study.

In a study done in Al-diwanyia teaching hospital, addition of tranexamic acid had no difference in bleeding profile and hospital stay of patients. However, this study had many limitations; one of which is its small sample size $(n=20)$. Unlike current study, the study conducted by Abdul-Kareem had used only tranexamic acid but hemostatics like vitamin-K, ethamsylate or fresh frozen plasma were not used. This study however shows that the use of tranexamic acid is safe in patients with snake bite. ${ }^{8}$ In current study, addition of tranexamic acid to conventional treatment lessened the hospital stay of patients. Overall, it seems that a combination of antifibrinolytics and hemostatics is better than either of them alone.

In this study, the conventional group achieved the similar result after $7^{\text {th }}$ day. Addition of tranexamic acid reduced hospitalization by median of 2 days. There was no mortality in either of treatment groups which supports that green snakes of hilly areas of Nepal are not lethally poisonous. ${ }^{5}$

\section{CONCLUSION}

In this study, addition of tranexamic acid to conventional treatment showed better result in terms of both primary (duration of hospital stay) and secondary (INR) outcome measures. Significant differences in mean INR levels were seen at day 5 and 6 of hospitalization in favor of tranexamic acid group. However, from $7^{\text {th }}$ day onwards the mean INR level of conventional group also showed improvement similar to that of tranexamic acid group. Overall, treatment with tranexamic acid reduced the median duration of hospital stay by two days.

\section{LIMITATION OF THE STUDY}

This is a preliminary open label study conducted in a single centre; hence the results of this study needs to be replicated in a double blinded study design including multiple centres. The cost effectiveness of using tranexamic acid was not 
assessed in the current study. The small sample size also adds to the limitation of the study. These limitations of present study present an opportunity for further studies in this area.

\section{ACKNOWLEDGEMENT}

We would like to express our sincere thanks to Dr Prakash
Thapa for his contribution in statistical analysis. We acknowledge all the patients and all our staff at medicine department for their timely assistance.

\section{CONFLICT OF INTEREST}

None

\section{REFERENCES}

1. Bhetwal BB, O'Shea M, Warell DA. Snake and snakebite in Nepal. Trop Doc. 1998; 28:193-5. DOI:10.1177/004947559802800401.

2. Joshi DD. An epidemiological study of snakebite cases in children of Nepal. Journal of Nepal Paediatric Society. 2010;13(3):977-81. DOI: 10.3126/jnps.v30i3.3915.

3. Wall F. The snakes of Ceylon. Colombo,H.R. Cottle, govt. printer, Biodiversity Heritage library .1921. DOI: 10.5962/bhl.title.53694

4. Ismail AK. Snakebite and envenomation management in Malaysia. Clinical Toxinology in Asia Pacific and Africa.2015:71-102. DOI: 10.1007/978-94-007-6288-6_54-1.
5. Kumar V, Maheshwari R, Verma HK. Toxicity and symptomatic identification of species involved in snakebites in the Indian subcontinent. J Venom Anim Toxins Incl Trop Dis. 2006;12(1):318.DOI: $10.1590 /$ S1678-91992006000100002.

6. Kornalik, F. The influence of snake venom on coagulation. Snake Toxins. 1997. p.323-833. DOI: 10.1016/0163-7258(85)90008-7.

7. Furie B, Furie BC. Molecular and cellular biology of blood coagulation. N EngI J Med 1992; 326(12):800-6. DOI:10.1056/NEJM 199203193261205.

8. Abdul-Kareem HK. Study of snake bites clinical signs, complications and management. Al Qadisiyah Medical Journal. 2017; 2(3):101109.w 